\title{
Dimensional ANd Shape Stability of Plywood Seat
}

\author{
Seid Hajdarevic, Murco Obucina, Muamer Delic, Alen Ibrisevic \& Mirza Cisija
}
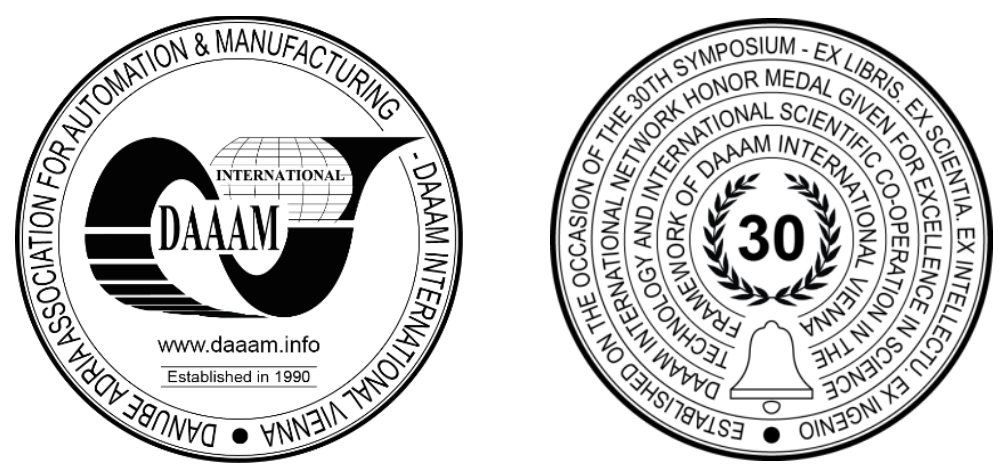

This Publication has to be referred as: Hajdarevic, S[eid]; Obucina, M[urco]; Delic, M[uamer]; Ibrisevic, A[len] \& Cisija, M[irza] (2019). Dimensional and Shape Stability of Plywood Seat, Proceedings of the 30th DAAAM International Symposium, pp.0318-0323, B. Katalinic (Ed.), Published by DAAAM International, ISBN 978-3-902734-22-8, ISSN 1726-9679, Vienna, Austria

DOI: $10.2507 / 30$ th.daaam.proceedings.042

\begin{abstract}
In this paper is performed the strain analysis of the common laminated wood seat shell exposed to the room conditions immediately after moulding. Experimental dimensional and shape stability evaluation is carried out by measuring the displacement of the three points on the backrest of the shell, which was placed in the indoor environment for 21 days. The results showed that the dominant displacement occurred in the initial days of testing during which the wood of the seat shell was achieved the equilibrium moisture content. Finite element analysis is conducted by 3D linear elastic model for orthotropic materials. Numerical calculation was used to determine displacement caused by the difference of the moisture content of the wood before and after the experimental examination. The numerical result showed smaller displacement of the backrest points than the measured displacements. The results also indicate that numerical calculations gave approximate data of the behaviour of the complex shape of laminated veneer products due to changes in moisture content of wood because of indoor condition change.
\end{abstract}

Keywords: seat shell; wood moisture content; strain; FEM.

\section{Introduction}

Plywood seat shells, laminated wood products that have curved and balanced structures made of veneer layers, are the basic elements of a certain types of chairs. Laminated structures have specific mechanical and physical properties that depend on the properties of individual veneers, veneers layout and parameters of production process.

The investigations in this domain of wood constructions are focused primarily on the analysis of mechanical properties of plywood. Different veneer layouts in plywood structure have a remarkable impact on plywood tensile strength [1]. Investigation of veneer layouts impact on strength of laminated wood and evaluation of mechanical properties of laminated wood was analysed by computer programs [2] and [3]. The stresses and strain state of laminated wood exposed to mechanical load was analysed by numerical methods. The results depend on simplifications and assumptions introduced in the numerical models. In-plane stress analyses of curved forms is not capable to calculating radial (interlaminar) stress and spatially complex curved structures require more complex analysis [4]. Linear elastic analysis of stress and strain for seat shells and laminated wood chair and the applicability of results as design tool have been explored [5], [6] and [7]. Deformations developed during the veneer products manufacture, after moulding and during 
use of the laminated veneer products were analyzed. Different fibre orientations, fibre deviations and moisture content of wood before and after moulding have a clear impact on shape stability laminated veneer products [8] and [9].

\section{Research objective and methodology}

The aim of this research was to analysis the dimensional and shape stability common laminated wood seat shell exposed to the room conditions immediately after moulding and to determine the effects of investigation approach on the results obtained by experimental and numerical methods.

The objective was to measure displacements of the three points on the backrest of the seat shell that was placed in the indoor environment for 21 days. Numerical calculation was used to determine displacement of the seat shell caused by the wood shrinkage as a result achieving the appropriate equilibrium moisture content during the experimental examination.

The plywood seat shell taken from manufacturing process and made from eleven plies of beech veneer was analyzed. Shape and dimensions of the seat shell are shown in the Fig. 1 (left). The thickness of all veneers was 1,5 mm and nominal value of plywood thickness was $16,0 \mathrm{~mm}$ and mean measured value $15,5 \mathrm{~mm}$. The plywood was made with a symmetric layout of veneers. First, second and fifth veneers of the symmetric half-thickness of plywood were oriented longitudinally and other layers with transverse oriented veneers. Urea-formaldehyde adhesive (UF) with catalyst (NH4Cl) was used to bond veneers with a spread rate of $160 \mathrm{~g} / \mathrm{m}^{2}$. The metal construction of the school chair was used to fix the shell and three gauges were to measure displacements, Fig. 1 (middle and right).
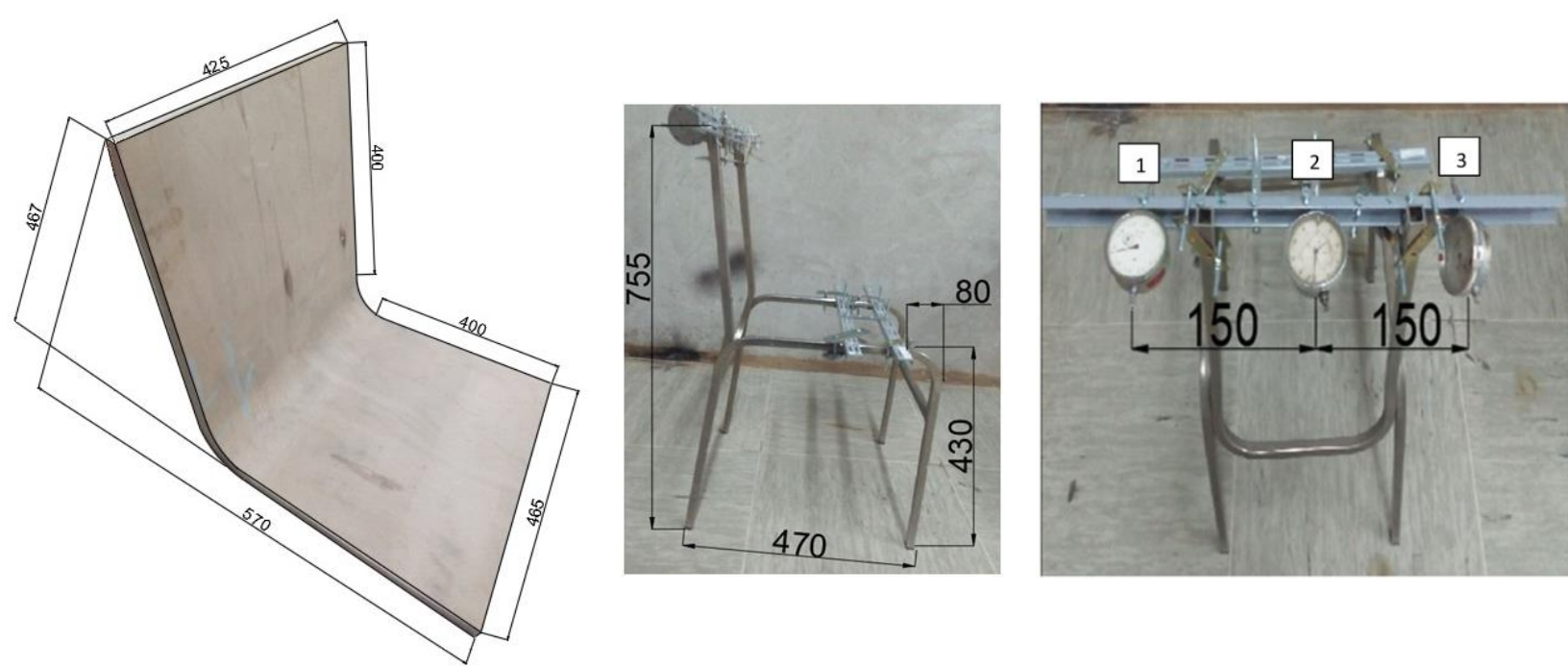

Fig. 1. Beech plywood seat shell (left), construction for fixing seat and gauges (middle and right)

Testing setup and used equipment are shown in Fig. 2. The shell was fixed to pedestal in the seat part zone with four screws. The horizontal displacements of the shell backrest at symmetrical three points were measured by the gauges. The position of the gauges (graduation: $0,01 \mathrm{~mm}$ ) was defined by the distances $(160 \mathrm{~mm})$ from the upper edge of the shell backrest. The air temperature and relative humidity $(\mathrm{RH})$ in the room during the testing were measured by digital thermometer - hygrometer (resolution: $0,1^{\circ} \mathrm{C}$ and $1 \%$ respectively).
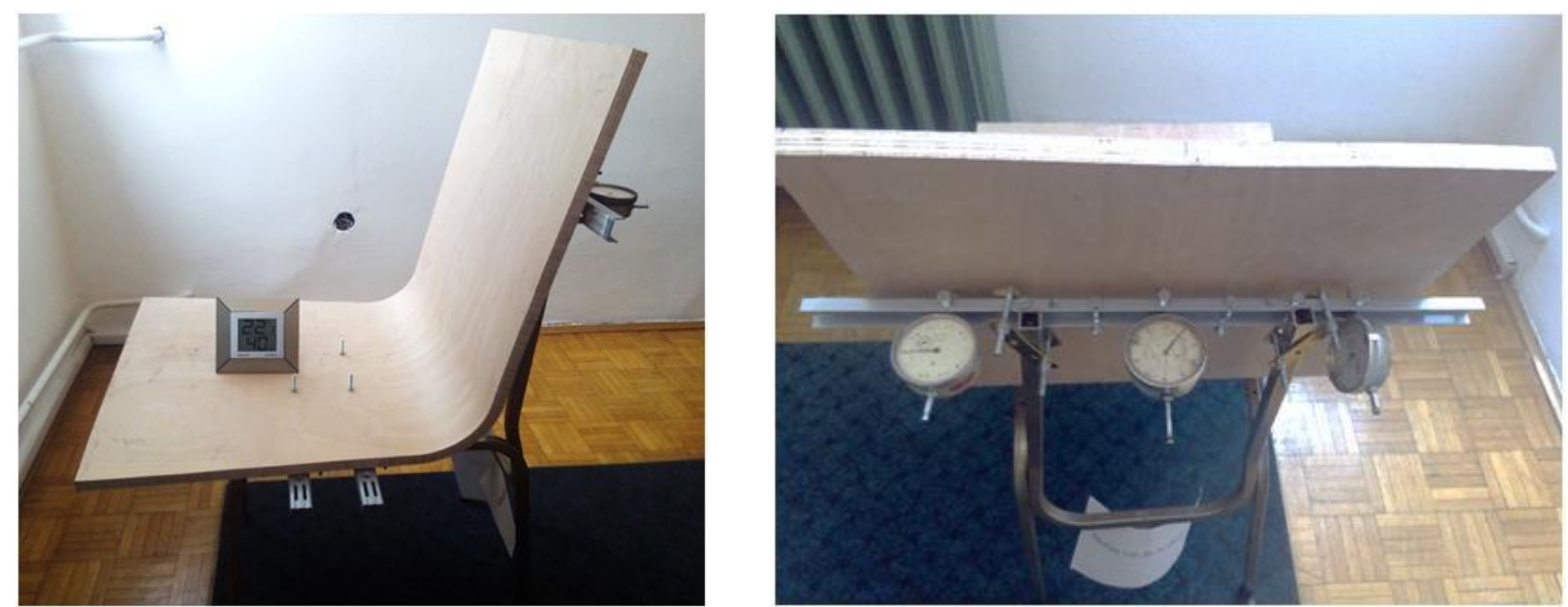

Fig. 2. Testing of the seat shell (left) and position of the gauges (right) 
The numerical 3D linear model for orthotropic material was solved by a finite element method, Fig. 3. The eleven layers were defined by a unique set of material properties and orientation of wood. The numerical results of the considered problem were obtained by using the Catia software package.
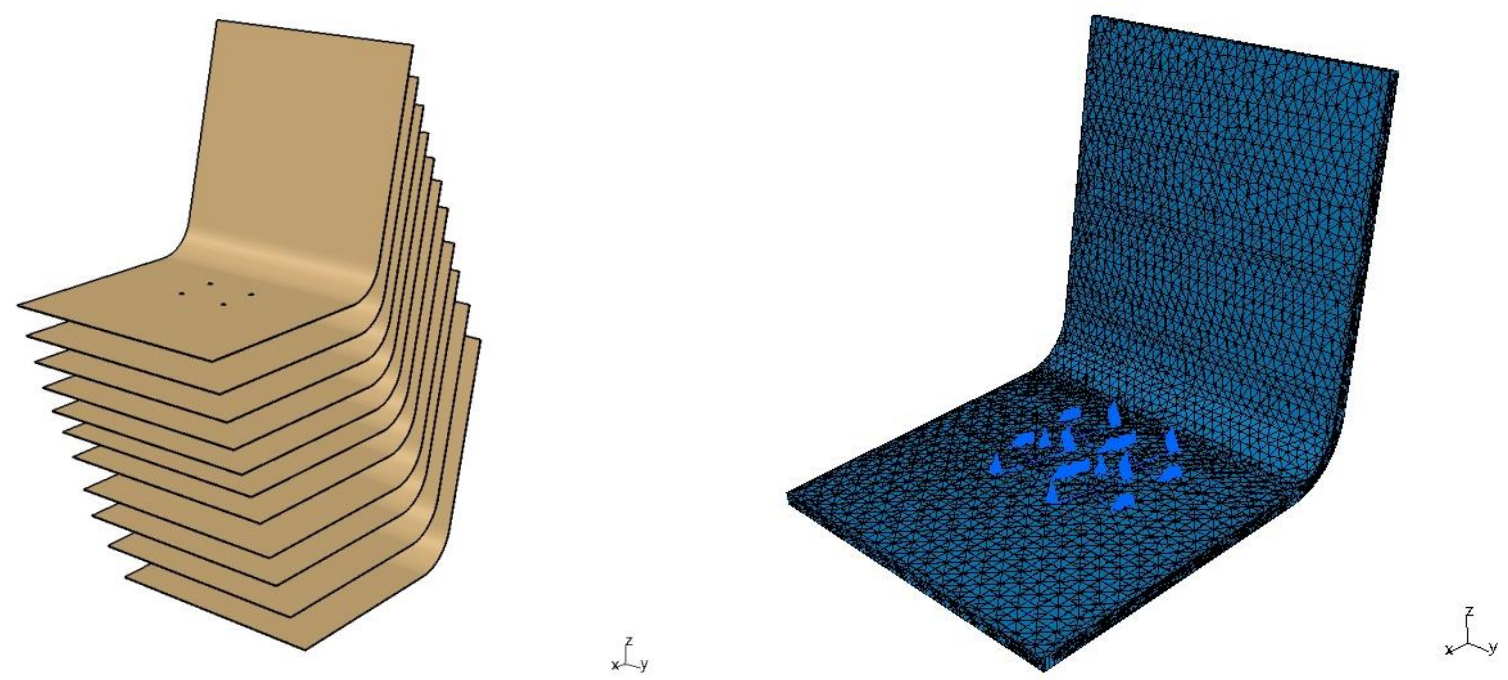

Fig. 3. Numerical model of the plywood seat shell: eleven layers (left) and mesh with boundary conditions (right)

The elastic properties and shrinkage (contraction) coefficients of the beech wood used in calculations are presented in Table 1 [10], [11]. Adhesive was neglected.

\begin{tabular}{|c|c|c|}
\hline \multirow{3}{*}{ Modulus of elasticity (GPa) } & $E_{L}$ & 13,969 \\
\hline & $E_{R}$ & 2,284 \\
\hline & $E_{T}$ & 1,160 \\
\hline \multirow{3}{*}{ Rigidity modulus (GPa) } & $G_{L R}$ & 1,645 \\
\hline & $G_{L T}$ & 1,082 \\
\hline & $G_{R T}$ & 0,471 \\
\hline \multirow{6}{*}{ Poisson’s ratio } & $v_{L R}$ & 0,450 \\
\hline & $v_{L T}$ & 0,510 \\
\hline & $v_{R T}$ & 0,750 \\
\hline & $v_{T R}$ & 0,360 \\
\hline & $v_{R L}$ & 0,075 \\
\hline & $v_{T L}$ & 0,044 \\
\hline \multirow{3}{*}{$\begin{array}{l}\text { Shrinkage (contraction) coefficients } \\
\text { (per } 1 \text { percentage point moisture } \\
\text { content change below FSP) }\end{array}$} & $\beta_{L}$ & $1,0 \cdot 10^{-4}$ \\
\hline & $\beta_{R}$ & $19,33 \cdot 10^{-4}$ \\
\hline & $\beta_{T}$ & $39,33 \cdot 10^{-4}$ \\
\hline
\end{tabular}

Table 1. Elastic properties and shrinkage coefficients of beech wood (Fagus sylvatica $\mathrm{L}.), \rho=0,75 \mathrm{~g} / \mathrm{cm}^{3}$ [10], [11]

\section{Results}

The experimental result of displacements of the three backrest points in the horizontal direction during 21 days is shown in Figure 3. The room air temperature and relative humidity $(\mathrm{RH})$ were measured on the same days. Data capture was performed twice a day, except the days of weekend, at the morning and at the afternoon.

The average value and standard deviation of the temperature during the test are $21,9{ }^{\circ} \mathrm{C}$ and $1,0{ }^{\circ} \mathrm{C}$ respectively. The average air relative humidity value and standard deviation are 41,4\% and 2,7 \% respectively. The literature table [11] gives that wood equilibrium moisture content is $7,9 \%$ by average values measured temperature and relative humidity. The average value and standard deviation of the seat shell wood moisture content after moulding i.e. at the test start were $10,67 \%$ and $0,45 \%$ respectively. The wood moisture content reached average value of $8,82 \%$ and standard deviation of $0,10 \%$ at the test end i.e. after 21 days. Therefore, the wood moisture difference at the test start and at the test end is $1,85 \%$ i.e. 1,85 percentage moisture content change below FSP.

During decrease of moisture content affected by the environmental conditions, shrinkage of the wood occurred. The changes of displacements recorded by three gauges, placed on the seat shell back during the 21 days, are shown as stacked lines in Figure 3. The displacements that were recorded all three gauges are in the same direction and in the direction of 
closing the seat shell. The curves are not overlap i.e. the values of displacement at the left (gauge 1), at the middle (gauge 2) and at the right (gauge 3) measuring point were not the same during the test.

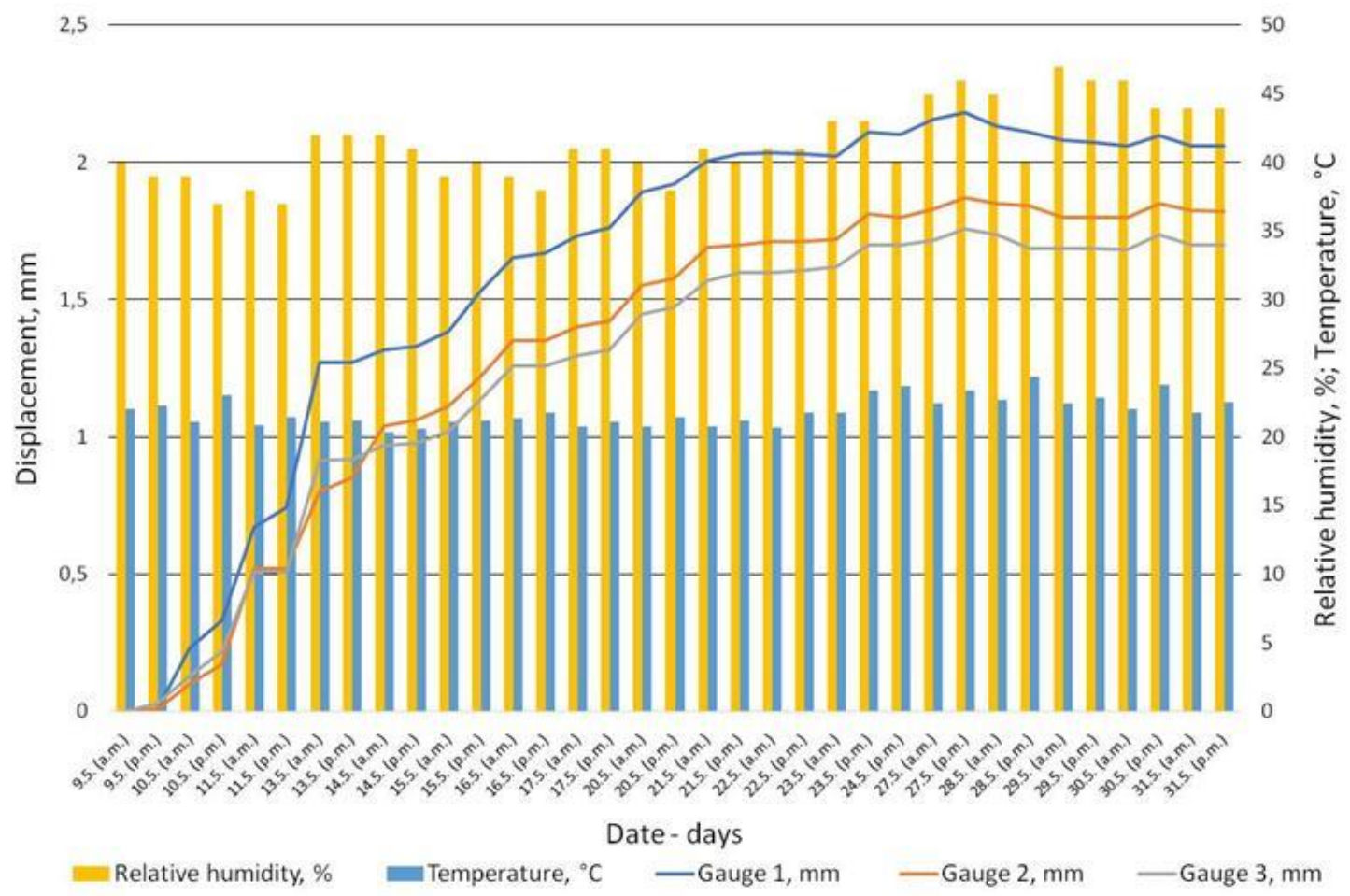

Fig. 4. Displacements of the three backrest points, temperature and humidity the room air

Initial and great increase of displacement, as expected, occurred in the first ten days of the test. The change of the displacement was slightly and the displacements become stagnant in the second part of the test. The maximum values of displacements are $2,18 \mathrm{~mm}$ at the left, $1,87 \mathrm{~mm}$ at the middle and $1,76 \mathrm{~mm}$ at the right measuring point. The largest displacement was recorded in the left (gauge 1) measuring point and the lowest value of displacement was obtained in the right (gauge 3) measuring point, which indicates twisting and changing the shape of the seat.

Strain was modeled by moisture content gradient regarding wood shrinkage of the seat shell layers. The moisture content gradient was $1,85 \%$ and represents the difference between the wood moisture content at the beginning and at the end of the test. The strain induced by the moisture below the fiber saturation point is dependent on the change of the moisture content. The equation for free shrinkage strain based on the internal moisture changes is $\boldsymbol{\varepsilon}_{M}=\boldsymbol{\beta} \cdot \Delta M$ where $\boldsymbol{\beta}$ is the matrix of the shrinkage (contraction) coefficients in longitudinal, radial and tangential direction and $\Delta M$ is the change of moisture content below the fibre saturation point. The wood temperature was assumed to be constant and the wood content of the moisture slightly changed during the test so that their effects on the mechanical properties of the wood were neglected.

The result of the numerical calculation comprising total displacement of the seat shell is shown in Figure 5.
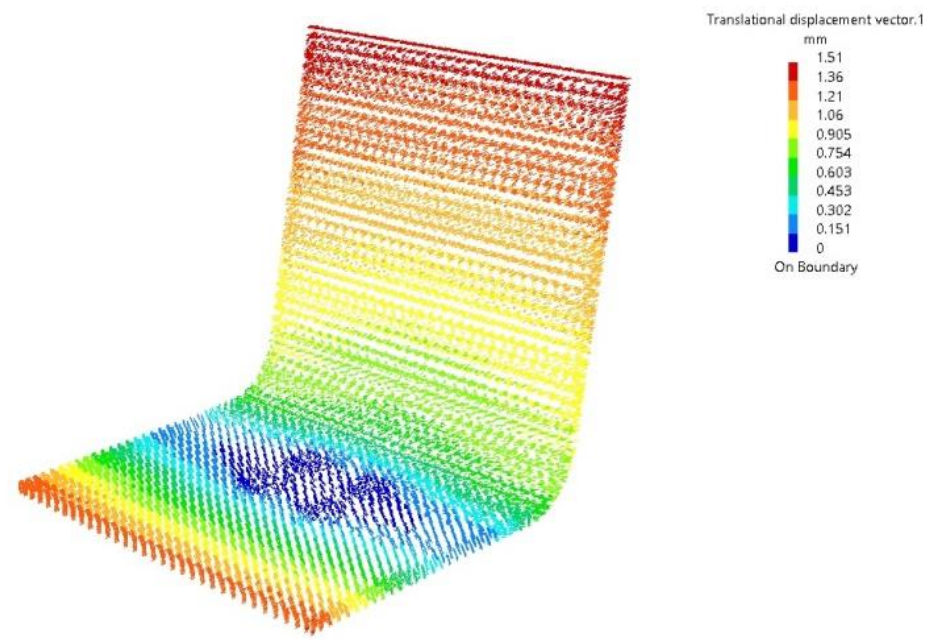

Fig. 5. Numerical result of the distribution of the total translational displacement 
The simulation of shrinkage of the wood cause displacement of the seat shell that have the similar magnitude to experimental results. The largest value of displacement $(1,5 \mathrm{~mm})$ is at the upper backrest edge. Displacements are minimal in the zone of fixing shell to pedestal and equal zero in the points of contacts with screws.

Displacement of the seat shell in the direction of the gauges ( $x$ axis) is shown in Figure 6. The results show that the displacement component in the direction of the gauges is dominant. The largest value of displacement $(1,47 \mathrm{~mm})$ is at the upper backrest edge. The great displacement values in the seat zone, from fixing points to the free seat edge, indicate the orthotropy inconsistency of the numerical model, but the direction of displacement show that the shrinkage simulaton is correct. The numerical result of the test points zone shows the same displacement direction as direction of displacement that was recorded by gauges. The numerical results shows approximately same values of displacements at the all three test points $\sim 1,13 \mathrm{~mm}$. The values are smaller than the displacements measured in the testing.

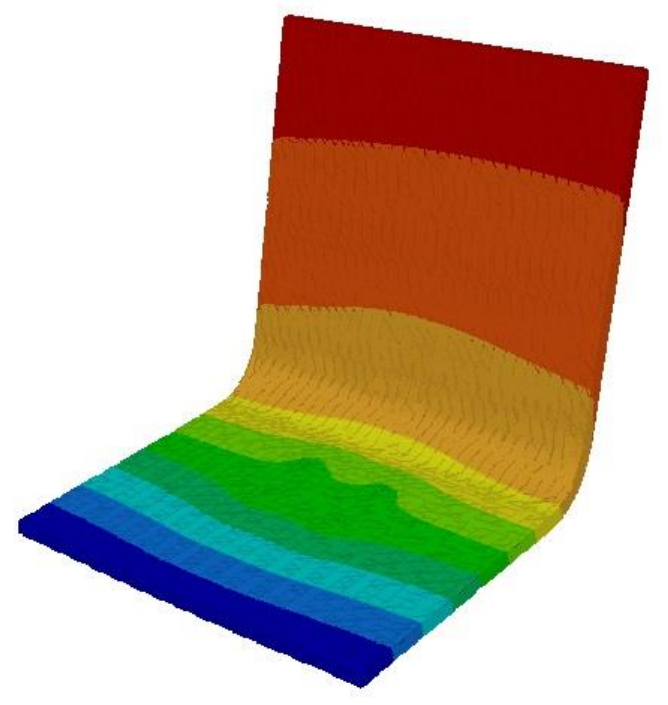

Translational displacement component.3

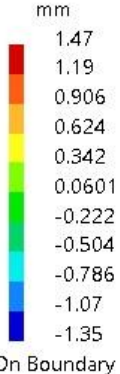

Fig. 6. Numerical result of the translational displacement component in the direction of the measurements of the gauges

\section{Conclusion}

An experimental investigation of the dimensional and shape stability and numerical simulation of the wood shrinkage of a common laminated wood seat shell exposed to the room conditions immediately after moulding have been preformed.

Dominant displacements and shape changed of the seat shell, based on the results of the test points at the backrest, has been occurred in the first ten days after moulding. Based on the stagnation of displacements, the equilibrium moisture content of the wood in the seat shell were achieved after that period of time. The difference of the wood moisture content of the seat shell after moulding and after exposed to the room conditions for 21 days is less than two percent which resulted low values of displacements measured in the points of backrest caused wood shrinkage. Different values of the displacement at the measuring points indicates low twisting and changing the shape of the backrest of the seat shell.

Numerical simulation of shrinkage of wood seat shell as a result of wood moisture content change obtained by test is performed. The numerical results show the same displacement direction and the similarity with experimental values. A developed numerical model with defined geometry and wood properties of leyers was not intended i.e. could not to simulate twisting of seat shell.

The test setup was allowed to collected data quite well. The experiment was time consuming and it was not practical to examining multiple samples. The numerical results are closely to the experimental data but the numerical model has lack of orthotropy consistency. The applied procedures can be successfully used to achieve approximate data of the behaviour of the complex shape of laminated veneer products due to changes in moisture content of wood because of indoor condition change.

Additional research needs to be done to set up optimal 3D orthotropy model of plywood seat shell and optimize this type of construction.

\section{Acknowledgments}

This paper was supported by the Federal Ministry of Education and Science of Federation of Bosnia and Herzegovina in the framework of the research project no. 0101-7991-11/18. 


\section{References}

[1] Jakimovska Popovska, V.; Iliev, B. \& Zlateski, G. (2017). Impact of veneer layouts on plywood tensile strength. Drvna industrija, 68 (2) pp. 153-161, doi: 10.5552/drind.2017.1634

[2] Boding, J. B.; Jayne, A. (1993). Mechanics of wood and wood composites, Krieger publishing Company, Malabar Florida

[3] Brezović, M.; Pervan, S.; Petrak, J. \& Prekrat, S. (2018). Metoda procjene svojstava uslojenog drva. Drvna industrija, 69 (1) pp. 49-54. doi.org/10.5552/drind.2018.1738

[4] Hajdarevic, S; Obucina, M. \& Mesic, E. (2017). Effect of veneer composition on the stiffness and stress of laminated wood. Proceedings of the 28th DAAAM International Symposium, Zadar, Croatia, November 18-11, pp. 03410350. dx.doi.org/10.2507/28th.daaam.proceedings.047

[5] Nestorović, B.; Skakić, D. \& Grbac I. (2011). Determining the characteristics of composite structure laminae by optical 3D measurement of deformation with numerical analysis. Drvna industrija, 62 (3) pp. 193-200, doi: 10.5552/drind.2011.1103

[6] Vratuša, S.; Kariž, M.; Ayrilmis, N. \& Kitek Kuzman, M. (2017). Finite element simulations of the loading and deformation of plywood seat shells. Eur. J. Wood Prod. DOI 10.1007/s00107-017-1160-4

[7] Hajdarević, S.; Obućina, M.; Mešić, E. \& Martinović, S. (2019). Stress and strain analysis of plywood seat shell. Drvna industrija, 70 (1) pp. 51-59, doi:10.5552/drvind.2019.1825

[8] Blomqvist, L.; Johansson, J. \& Sandberg, D. (2013). Basic knowledge of wood properties for improved performance of laminate veneer products. Pro Ligno, Vol.9 No 4 2013, pp. 549-556, ISSN-L 184-4737

[9] Blomqvist, L.; Berg, S. \& Sandberg, D. (2019). Distortion in laminated veneer products exposed to relative-humidity variations - Experimental studies and finite-element modelling. BioResources, 14(2), pp. 3768-3779. DOI: 10.15376/biores.14.2.3768-3779

[10] Smardzewski, J. (2008). Effect of wood species and glue type on contact stresses in a mortise and tenon joint. Journal of Mechanical Engineering Science, 222 (12): 2293-2299. doi.org/10.1243/09544062JMES1084

[11] Forest Products Laboratory. (2010). "Wood handbook wood as an engineering material," General technical report FPL GTR-190, U.S, Dept. of Agriculture, Forest Service, Forest Products Laboratory, Madison, WI 